\title{
SOCIALTHOUGHT\& RESEARCH
}

A Continuation of the Mid-American Review of Sociology

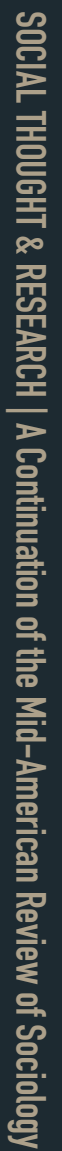
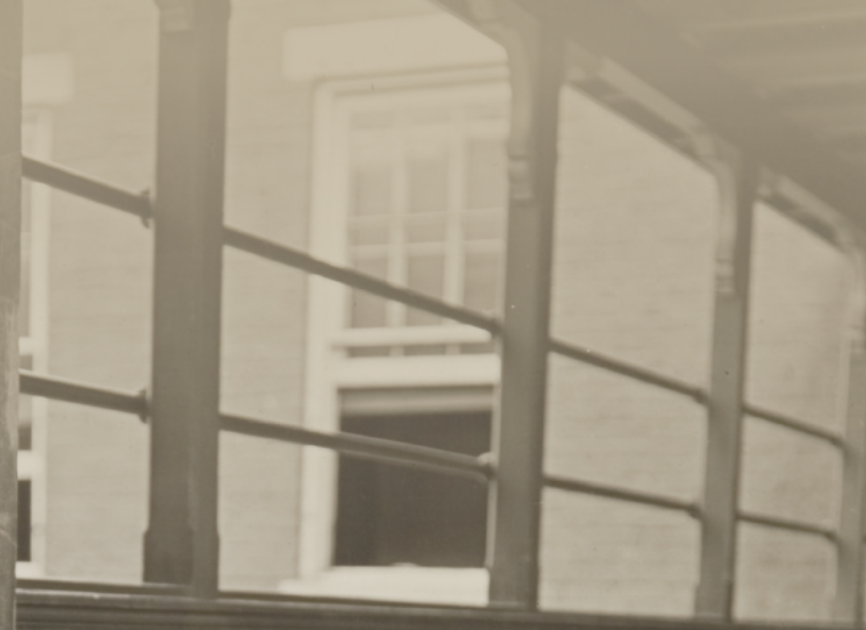

VOL.

31

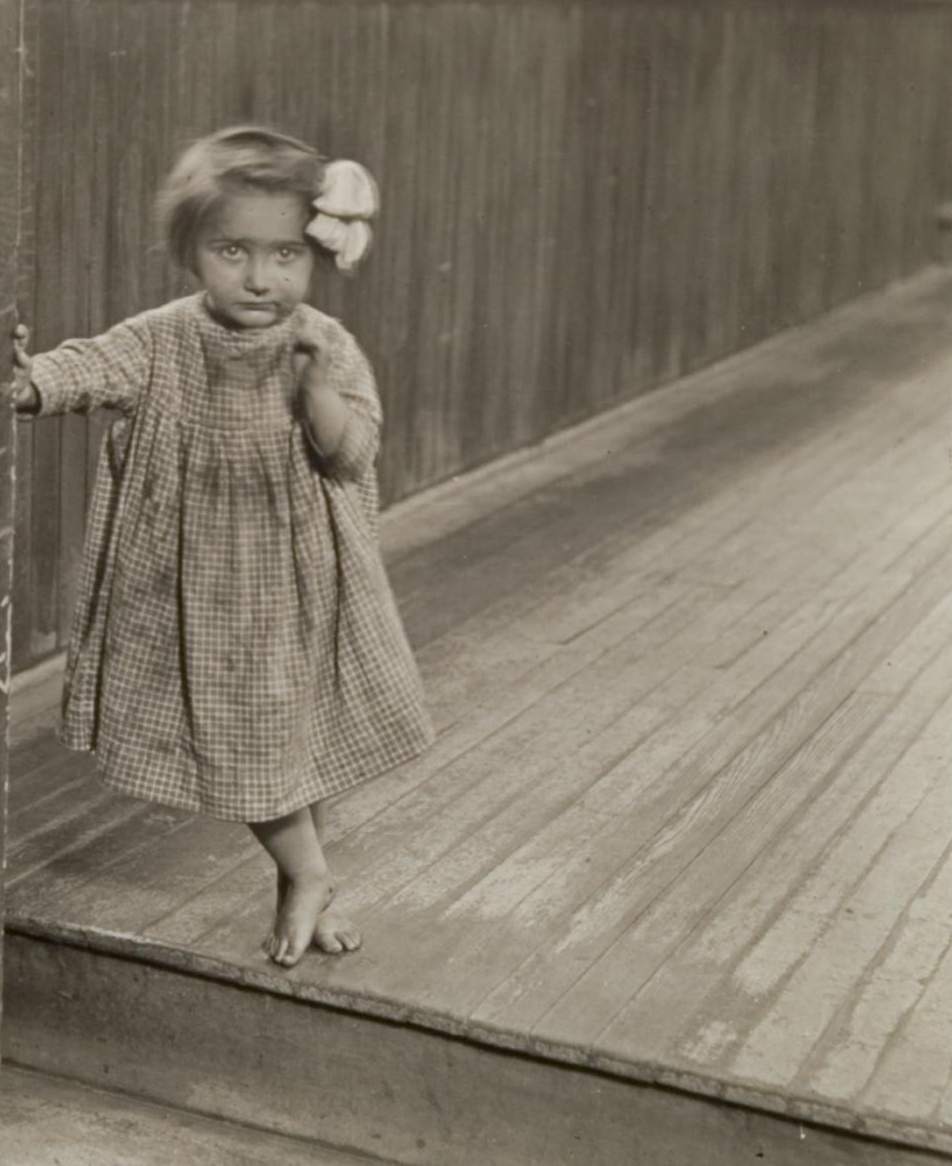




\section{Social Thought \& Research Vol. 31, 2010}

\section{Co-Editors}

RACHEL CRAFT

University of Kansas

Stephanie Decker

University of Kansas

ILANA DEMANTAS

University of Kansas

Kevin McCannon

University of Kansas

RuSSEll SCHLOEMER University of Kansas

JASON STERnBERG University of Kansas

\section{Staff}

Aislinn Addington James Ordner

Chelsea Bailey

CARrie Wendel-Hummell

POOYA NADERI 


\section{Cover Art:}

Little Orphan Annie in a Pittsburgh Institution (1909), Lewis Wickes Hine

Lewis Hine (1874-1940) was an American sociologist and photographer who attempted to use photography as a means to convey messages of social reform. Ultimately the images he captured would become instrumental in convincing legislators to reform child laws in the United States. He studied at the University of Chicago, Columbia University and New York University before teaching at the Ethical Culture School in New York City. Many of his classes focused on photography and focused on the immigrants coming into Ellis Island before he left the school and became a full time photographer for the Russell Sage Foundation in Pittsburgh. Later he would also work for the National Child Labor Committee, American Red Cross, Tennessee Valley Authority and Works Progress Administration National Research Project before falling from prominence in the late 1930s and falling into poverty himself and then dying on November $3^{\text {rd }}, 1940$.

Little Orphan Annie was taken during his time in Pittsburgh and was titled in reference to the famous Little Orphan Annie comic strip that described an orphan girl who was forced to work to earn her keep. Hine wrote the following to the Child Labor Committee when he took the photo: "Olga Schubert. The little 5-year-old after a day's work helping her mother in the Biloxi Canning factory, began about 5:00 A.M., was tired out and refused to be photographed. The mother said, 'Oh, she's ugly.' Both she and other persons said picking shrimp was very hard on the fingers."

Our thanks to Merry A. Foresta (American Photographs: The First Century, 1996) and PhotoCollect (http://photocollect.com) for their assistance in collecting biographical information on Lewis Wickes Hine. 


\title{
Editorial Advisory Board
}

\author{
Robert J. Antonio University of Kansas \\ RoSLYN WALLACH BOLOGH CUNY-College of Staten Island \\ JASON CAPPS Seattle University \\ GÖRAN DAHL Lund University, Sweden \\ DAVID EKERDT University of Kansas \\ ERIC HANLEY University of Kansas \\ SHIRLEY A. HILl University of Kansas \\ STEPHEN KALBERG Boston University \\ CHANGHWAN KIM University of Kansas \\ LIZ LEGERSKI University of North Dakota \\ LEWIS A. MENNERICK University of Kansas \\ MEHRANGIZ NAJAFIZADEH University of Kansas \\ EBENEZER OBADARE University of Kansas \\ HAROLD L. ORBACH Kansas State University \\ DAVID N. SMITH University of Kansas \\ MurRAY E. G. SMITH Brock University-Ontario, Canada \\ WILLIAM G. STAPLES University of Kansas \\ MARY K. ZIMMERMAN University of Kansas
}




\title{
ISSN: 1094-5830
}

Social Thought \& Research (STAR) is published annually. You may contact the journal at:

\author{
Editors \\ SOCIAL THOUGHT \& RESEARCH \\ Department of Sociology \\ University of Kansas \\ Fraser Hall, Room 709 \\ 1415 Jayhawk Blvd. \\ Lawrence, KS 66045-7556 \\ Email: starjournal@ku.edu \\ Website: http://web.ku.edu/ starjrnl
}

\section{Subscription Rates for 2010-2011}

Individuals: $\$ 30$

Institutions: $\$ 50$

Subscriptions for addresses outside of the United States, add $\$ 10$ for postage.

All payments should be made to Social Thought \& Research. Back issues of STAR are available for $\$ 30$ each.

\section{Manuscript Submissions:}

Format: Submissions should include: a cover letter with author contact information, including an email address; a cover page, including the title of your manuscript, keywords, and a 200 word abstract; and one Microsoft Word compatible manuscript. If a manuscript is considered for revision and resubmission, STAR will advise authors regarding additional format. Please see our website for additional details.

Submissions: Cover letter, cover page, and manuscript should be submitted as attachments in an email to starjournal@ku.edu. There is presently no fee for submitting articles or book reviews to STAR.

Inquiries: Inquiries from authors or concerning business matters, subscriptions, change of address, advertising rates, and claims should be directed to the above address. 


\section{TABLE OF CONTENTS}

Vol. 31, 2010

\section{On the Cover}

Russell Schloemer (University of Kansas)

\section{Acknowledgments}

Invited 2009 Carroll D. Clark Lecturer AT THE University OF KANSAS

\section{Interview with Annette Lareau}

Prepared by Annette Lareau, M. Katherine Mooney,

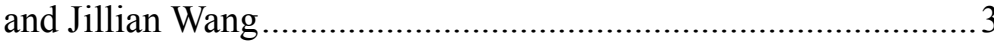

Invited 2009 Sociology Graduate Student Sponsored Lecture Series at the University of Kansas

Interview with Colin Jerolmack

Prepared by Rachel Craft 15

\section{FEATURED ARTICLES}

\section{Michael J. Lynch, Temple University}

Sex in Second Life: Scripts, Presence, and Bounded Authenticity in a Virtual Environment

William Mingus, University of Illinois, Chicago

Bradley Zopf, University of Illinois, Chicago

White Means Never Having to Say You're Sorry

\section{Bridget K. Welch, Western Illinois University} Anna E. Kosloski, Iowa State University

"Mario Kart" Nintendo Wii as an Active Learning Technique for Teaching Inequalities 


\section{BOOK REVIEW}

\section{Henricks, Kasey, Loyola University}

Fade to Black and White: Interracial Images in Popular

Culture (2009) by Erica Chito Childs 


\section{Acknowledgments}

The editors of Social Thought and Research would like to thank all of the individuals involved in the production of Volume 31: Paula Courtney of the College of Liberal Arts and Sciences Digital Media Services at the University of Kansas (KU) for their help formatting this volume for publication, and Kate Mayer and Sherèe Peterson at the Spencer Museum of Art at KU for her help selecting the cover image. We also want to thank graduate students, faculty, and staff in the Department of Sociology at KU for their continued support of STAR, including technical and editorial expertise and advice. We especially want to thank all of our anonymous reviewers for their time spent reviewing the submissions to this volume. And finally, we thank all the authors who submitted their work for Volume 31 for their patience, diligence, and effort put into drafting and finishing their work for publication.

--Rachel Craft 